Available online at GSC Online Press Directory

GSC Biological and Pharmaceutical Sciences

e-ISSN: 2581-3250, CODEN (USA): GBPSC2

Journal homepage: https://www.gsconlinepress.com/journals/gscbps

(RESEARCH ARTICLE)

\title{
Total phenolic content, antioxidant and antimicrobial activities of seeds and callus of Trigonella foenum-graecum Linn.
}

\author{
Osman Magdoleen G ${ }^{1}$, Daffalla H M 1, ${ }^{*}$, Ahmad Magda M M ${ }^{1}$, Ali Kauther Sir el-khatim ${ }^{2}$, Saleh Salma A ${ }^{3}$ and \\ Hamza Abdelhalim A ${ }^{3}$ \\ 1 Department of Plant Cell and Tissue Culture, Commission for Biotechnology and Genetic Engineering, Khartoum, Sudan. \\ 2 Department of Biotechnology, College of Applied and Industrial Sciences, University of Bahri, Khartoum North, Sudan. \\ ${ }^{3}$ Department of Biochemistry, Commission for Biotechnology and Genetic Engineering, Khartoum, Sudan.
}

Publication history: Received on 06 February 2020; revised on 17 February 2020; accepted on 28 February 2020

Article DOI: https://doi.org/10.30574/gscbps.2020.10.3.0033

\begin{abstract}
Development of an efficient system for callus induction on different explants of fenugreek. Comparing phenolic, antioxidant and antimicrobial activities of seed and calli of different fenugreek explants. Fenugreek is a well-known medicinal plant for pharmaceutical and nutraceutical properties. For callus induction, three explants were used viz. hypocotyl, root, and cotyledons. The explants were cultured on MS medium supplemented with 2, 4-D, NAA and TDZ in different concentrations $(0.5-6 \mathrm{mg} / \mathrm{L})$. Antioxidant activity using DPPH and Folin-ciocalteu assays, and antimicrobial activity of calli and seed extracts were evaluated. Friable callus was successfully induced on all explants and by all PGRs except 2, 4-D which failed to stimulate callus formation on root explant. Root segment was the better explants in callus induction with maximum fresh weight $5.29 \mathrm{~g}$ with TDZ at $2 \mathrm{mg} / \mathrm{L}$ and highest callus index was 4.3 with TDZ at $0.5 \mathrm{mg} / \mathrm{L}$. Hypocotyl callus showed the highest phenolic content (246.9 mg GAE/g DW) compared to root callus (243.5 mg GAE/g DW), seed (176.2 mg GAE/g DW) and then cotyledons callus (64.9 mg GAE/g DW) with the lowest value. On the other hand, seed exhibited $44.3 \%$ antioxidant activity compared to $34.7 \%$, $24.3 \%$ and $16.7 \%$ recorded by cotyledons, hypocotyl, and root calli, respectively. Regarding antimicrobial activity of studied fenugreek extracts, hypocotyl callus exhibited the maximum zone of inhibition recorded (19 mm) against E. coli. Callus of fenugreek showed potential biological activities over seed-extract.
\end{abstract}

Keywords: Fenugreek; Callus; TDZ; Diameter zone of inhibition; Explants

\section{Introduction}

Fenugreek (Trigonella foenum-graecum Linn, Fabaceae) is an old and a common traditional medicinal and food plant in northern and eastern Africa, Middle East, China and India [1]. Several ailments have been cured traditionally with fenugreek extracts including colic flatulence, dysentery, diarrhea, dyspepsia with loss of appetite, correcting gastric troubles, regulating the digestive system, and relief in joints pains particularly of old age [1, 2]. Moreover, various biological activities were fulfilled on fenugreek seeds extracts including carminative, tonic, aphrodisiac and anticancer properties [3]. The seeds extract appeared to contain various metabolites including polysaccharide, galactomannan, different saponins such as diosgenin, yamogenin, mucilage, lipids, flavonoids, apigenin, luteolin, quercetin and alkaloids such as choline and trigonelline [4]. Leaves extract like seeds, was also studied for various nutritional and therapeutical properties. Phytochemical analysis showed that fenugreek leaves contain saponins, ascorbic acid and $\beta$ carotene. However, phenolic and flavonoids are the main compounds reported in different fenugreek parts which are responsible for its antioxidants capability [2].

\footnotetext{
* Corresponding author: Daffalla H M
} 
Plant tissue culture techniques have been developed for rapid, large-scale production of cells and their secondary compounds, therefore, offer an uninterrupted and reliable supply of secondary metabolites in higher concentrations compared to the whole plants [5]. Callus induction is the initial phase both for establishing a cell suspension system that affected by the type of explant, plant growth regulators and genotype. Aasim et al. [6] reviewed the plant tissue culture research on fenugreek found that most of the work was done on callus and cell cultures for important metabolites production. Many important phytochemicals have been detected in in vitro culture of fenugreek such as diosgenin in callus [7, 8] or in cell suspensions [9], isoflavonoid in cell suspension [10], 4-hydroxyisoleucine in callus [11], choline, trigonelline and carpaine alkaloids in callus [12]. Establishment of callus culture for fenugreek has been reported by different authors using different types of explants. However, the most responsive explant of fenugreek for callus induction was varied as leaf [9], shoot apex [13, 14], cotyledons [15], hypocotyl [16], root [7, 17] and embryonic axis [11]. Regarding the optimum plant growth regulators suitable for maximum callus induction, some author determined 2, 4-D while other selected NAA or combined with cytokinin as reported by Hassan and Jassim [12]. The variations in callusing liability and ability of fenugreek explants can be attributed to the genotype effect. Screening of 21 Iranian landraces of fenugreek for callus induction showed significant dissimilarity in callus induction between studied genotypes [11]. The aim of this study was to develop an efficient system for callus induction on different explants of fenugreek. Then comparing the phenolic, antioxidant and antimicrobial potentials between seed and calli produced from different fenugreek explants.

\section{Material and methods}

\subsection{Callus induction procedure}

Mature seeds of Trigonella foenum-graecum (fenugreek) were obtained from a local market at Khartoum, Sudan. Seeds were surface sterilized in $10 \%$ solution of clorox $^{\circledR}(0.5 \%$ free chlorine) for $15 \mathrm{~min}$ and then rinsed four times by sterile distilled water. Thereafter, the seeds were cultured on Murashige and Skoogs (MS) basal medium [18] supplemented with $3 \%$ sucrose and $0.7 \%$ agar, at a pH of 5.8. The cultures were incubated under dark for 10 days.

The 10-days-old in vitro germinated seedlings of fenugreek were excised to three explants namely hypocotyl (5-10 $\mathrm{mm}$ ), roots (3-5 mm) and cotyledons (Fig. 1). The explants were inoculated on MS medium fortified with either 2, 4dichloro-phenoxy acetic acid (2, 4-D), naphthalene acetic acid (NAA), or thidiazuron (TDZ) at different concentrations $(0.0,0.5,1.0,2.0,4.0$ and $6.0 \mathrm{mg} / \mathrm{L})$. The cultures were incubated at $25 \pm 2{ }^{\circ} \mathrm{C}$ under $16 \mathrm{~h} /$ day photoperiod using cool white fluorescent lights (1000 Lux). Callus induction performance was assessed qualitatively after six weeks of culture using percentage, callus color, and size index as 1: callus on one end of explant, 2: callus on two ends of explant, 3: callus on two ends and one side of explant, 4: callus on two ends and two sides of explant, 5: callus on two ends, two sides and surface of explant. Then, after another week, calli were harvested off the cultures and fresh weight of callus per explant was obtained.

\subsection{Plant material and extracts preparation}

Calli (7 weeks old) derived from hypocotyl, cotyledons and root explants were freeze-dried and crushed into homogenous particles. Fenugreek seeds were washed with distilled water to remove foreign matter and then air-dried at room temperature. The dried seeds were grounded using a blinder and sifted through a mesh sieve to obtain a fine powder. Ten grams of each of calli and seed materials were macerated in $200 \mathrm{~mL}$ of $80 \%$ methanol with interval shaking at room temperature for $48 \mathrm{~h}$. Then, extracts were filtered through Whatman filter paper No. 1. The residues were re-extracted twice under the same condition to ensure complete extraction. Extracts were concentrated at $45^{\circ} \mathrm{C}$ under reduced pressure with a rotary evaporator and their dry masses were recorded. Dried extracts were stored at 4 ${ }^{\circ} \mathrm{C}$ until experimental use.

\subsection{Determination of total polyphenol content}

The concentration of phenolics in fenugreek seed and calli (roots, cotyledon and hypocotyls) extracts were determined using the Folin-Ciocalteu method [19]. Methanolic solutions of the fenugreek samples with a concentration of $1 \mathrm{mg} / \mathrm{mL}$ were used for the analysis. The reaction mixture was prepared by mixing $0.5 \mathrm{~mL}$ of the samples with $2.5 \mathrm{~mL}$ of $10 \%$ Folin-Ciocalteu's reagent dissolved in water and $2.5 \mathrm{~mL}$ of $7.5 \% \mathrm{NaHCO}_{3}$. Blank was concomitantly prepared, containing $0.5 \mathrm{~mL}$ methanol, $2.5 \mathrm{~mL} \mathrm{10 \%} \mathrm{Folin-Ciocalteu's} \mathrm{reagent} \mathrm{dissolved} \mathrm{in} \mathrm{water} \mathrm{and} 2.5$ $\mathrm{mL}$ of $7.5 \%$ of $\mathrm{NaHCO}_{3}$. The samples were thereafter incubated in a thermostat at $30{ }^{\circ} \mathrm{C}$ for $90 \mathrm{~min}$. The absorbance was determined using a spectrophotometer at $\lambda_{\max }=765 \mathrm{~nm}$. The samples were prepared in triplicate for each analysis and the mean value of absorbance was obtained. The same procedure was repeated for the standard solution of gallic acid and the calibration line was construed. Based on the measured absorbance, the concentration of 
phenolics was read $(\mathrm{mg} / \mathrm{mL})$ from the calibration line; then the content of phenolics in extracts was expressed in terms of gallic acid equivalent (mg of GA/g dry weight of extract).

\subsection{Free radical scavenging assay}

The antioxidant activity of the four fenugreek extracts was determined by the 1, 1-diphenyl-2-picrylhydrazyl (DPPH) inhibition method as described by Shyur et al. [20] with some modifications. Various concentrations (1.56-100 $\mu \mathrm{g} / \mathrm{mL})$ were prepared from stock solutions $(1 \mathrm{mg} / \mathrm{mL}$ in $98 \%$ ethanol) of the fenugreek extracts. For each concentration of the extracts, $0.9 \mathrm{~mL}$ Tris- $\mathrm{HCl}$ and $1 \mathrm{~mL}$ DPPH $(0.1 \mathrm{mM})$ were added in tubes. Same volumes of Tris$\mathrm{HCl}$ and DPPH were added to $0.1 \mathrm{~mL}$ ethanol serving as control used, while $0.9 \mathrm{~mL}$ of Tris-HCL was added to $1.1 \mathrm{~mL}$ ethanol used as a blank sample. Then the tubes were incubated at room temperature in the dark for $30 \mathrm{~min}$. The absorbance of the resulting mixture was measured at $517 \mathrm{~nm}$ in a spectrophotometer. The scavenging ability of the plant extract was calculated using the formula:

Scavenging activity $(\%)=\frac{\text { Acontrol }- \text { A sample }}{A \text { control }} \times 100$

The total antioxidant activity was expressed as ascorbic acid equivalent/g dry weight extract.

\subsection{Antimicrobial activity}

The extracts of seeds and calli of fenugreek were tested in vitro for their antibacterial and antifungal activities against difference pathogenic organisms. Fenugreek extracts $(100 \mathrm{mg} / \mathrm{mL})$ were tested against Pseudomonas aeruginosa (ATCC 27853), Escherichia coli (ATCC 25922) Salmonella typhi (ATCC 0650), Staphylococcus aureus (ATCC 25923), and Candida albicans (ATCC 7596) using agar diffusion method [21] with minor modifications.

\subsection{Data collection and statistical analysis}

The results were observed at regular intervals and data were collected from three independent experiments and analyzed by using analysis of variance procedure (ANOVA) on Microsoft Excel program. Means were separated by Duncan's multiple range test (DMRT) and presented as average \pm standard error.

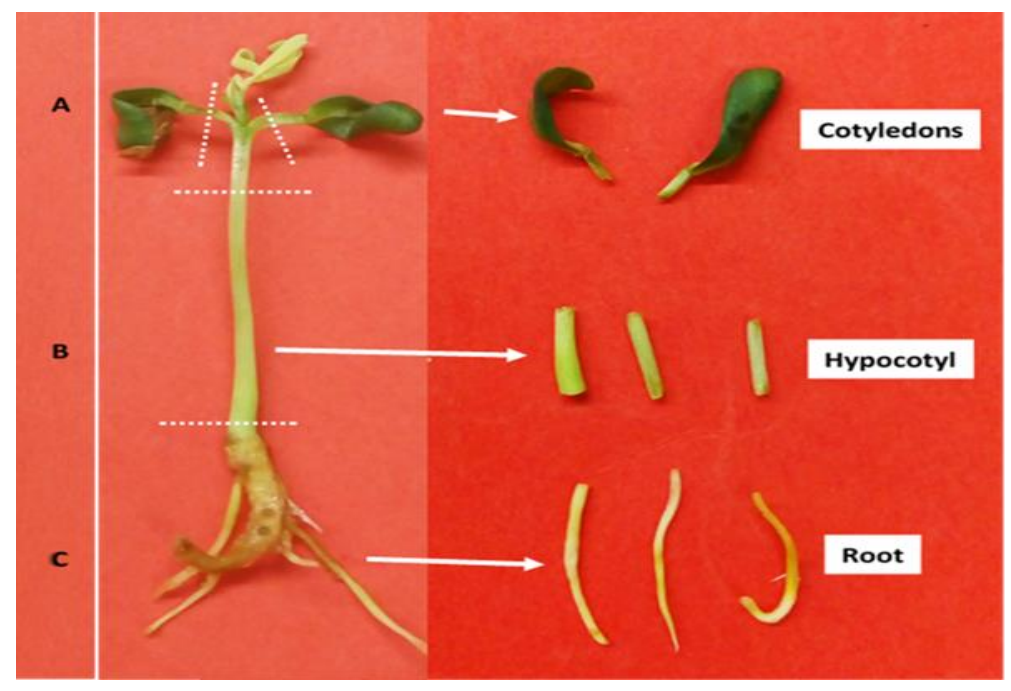

Figure 1 Explants perpetration from 10-days-old in vitro germinated seedlings of fenugreek

\section{Results and discussion}

\subsection{Callus induction}

All cultured fenugreek explants developed a friable callus on both TDZ and NAA-amended media. Root explants on cultured 2, 4-D augmented media did not produce any callus. Both the quality and quantity of callus induced were vary depending on the types of explant and the PGRs used (Tables 1 and 2, Figure 1). 
All three types of explants cultured on TDZ augmented medium recorded 100\% callusing (Table 1). While hypocotyl explants cultured on medium fortified with 2, 4-D and NAA (both at $0.5 \mathrm{mg} / \mathrm{L}$ ) produced $100 \%$ and $94 \%$, respectively. The highest callus size obtained was 4.2 on hypocotyl explant cultured on $4 \mathrm{mg} / \mathrm{L}$ TDZ supplemented medium (Table 1). These results suggest that TDZ was the most effective PGRs for callus formation compared to NAA and 2, 4-D. Also, the hypocotyls segment was the most responsive explant compared to cotyledon and root explants. Within two varieties of fenugreek studied by Lohvina et al. [22] stem showed the highest percentage of callogenesis than leaf explant. Similarly, the stem segments give the best callogenesis rate compared to the leaf and root explants of fenugreek [7].

The highest fresh weight of callus obtained was $5.29 \pm 0.4 \mathrm{~g}$ on hypocotyl explants using medium supplemented with 2 $\mathrm{mg} / \mathrm{L}$ TDZ (Table 2). However, the value was not significantly $(P<0.05)$ different from that recorded by root explants ( $4.77 \pm 0.5 \mathrm{~g}$ ) cultured on $0.5 \mathrm{mg} / \mathrm{L} \mathrm{TDZ}$ medium and cotyledon explants cultured on $2 \mathrm{mg} / \mathrm{L}$ TDZ medium. The significantly $(P<0.05)$ lowest value of callus fresh weight recorded was $0.30 \pm 0.1 \mathrm{~g}$ on cotyledon explants cultured on medium supplemented with $0.5 \mathrm{mg} / \mathrm{L}$ NAA (Table 2). Oncina et al. [7] found that stem segments produced maximum callus fresh and dry weights compared to the leaf and root explants of fenugreek. In contrast, Prabakaran and Ravimycin [15], Elaleem et al. [23] and Vaezi et al. [24] found that cotyledon explants were better in callus production than the hypocotyl explants of fenugreek. Its evidence that callus induction in fenugreek is not only affected by the level of plant growth regulators and type of explants but also by genotypes [14].

Table 1 Qualitative measurements of callus induction on different explants of fenugreek after 6 weeks of culture

\begin{tabular}{|c|c|c|c|c|c|c|c|c|}
\hline \multirow{2}{*}{\multicolumn{2}{|c|}{ PGRs (mg/L) }} & \multicolumn{3}{|c|}{ Callusing (\%) } & \multicolumn{3}{|c|}{ Callus size index } & \multirow{2}{*}{$\begin{array}{l}\text { Color } \\
\text { H, C, R }\end{array}$} \\
\hline & & \multirow{2}{*}{$\frac{\mathbf{H}}{0}$} & \multirow{2}{*}{$\begin{array}{l}\text { C } \\
0\end{array}$} & \multirow{2}{*}{$\begin{array}{l}\mathbf{R} \\
0\end{array}$} & \multirow{2}{*}{$\frac{\mathbf{H}}{0}$} & \multirow{2}{*}{$\frac{\mathrm{C}}{0}$} & \multirow{2}{*}{$\begin{array}{l}\mathbf{R} \\
0\end{array}$} & \\
\hline Contr & & & & & & & & - \\
\hline TDZ & 0.5 & 100 & 100 & 100 & 3.3 & 3.5 & 4.3 & Light green \\
\hline & 1 & 100 & 100 & 100 & 3.2 & 3.3 & 4.0 & \\
\hline & 2 & 100 & 100 & 100 & 3.3 & 3.5 & 2.7 & \\
\hline & 4 & 100 & 100 & 100 & 4.2 & 3.0 & 4.2 & \\
\hline & 6 & 100 & 100 & 100 & 3.3 & 3.0 & 4.0 & \\
\hline NAA & 0.5 & 94 & 50 & 100 & 2.3 & 2.2 & 2.5 & Green \\
\hline & 1 & 81 & 75 & 100 & 2.2 & 2.0 & 2.3 & \\
\hline & 2 & 75 & 68 & 75 & 2.2 & 2.5 & 2.2 & \\
\hline & 4 & 75 & 60 & 56 & 2.5 & 2.5 & 2.2 & \\
\hline & 6 & 69 & 50 & 31 & 2.2 & 2.0 & 2.0 & \\
\hline $2,4-D$ & 0.5 & 100 & 58 & 0 & 2.2 & 2.5 & 0 & Yellowish green \\
\hline & 1 & 100 & 66 & 0 & 2.3 & 2.5 & 0 & \\
\hline & 2 & 25 & 66 & 0 & 2.5 & 2.2 & 0 & \\
\hline & 4 & 16 & 33 & 0 & 2.0 & 2.2 & 0 & \\
\hline & 6 & 16 & 16 & 0 & 2.0 & 2.0 & 0 & \\
\hline
\end{tabular}

PGRs; plant growth regulators, H; hypocotyl, C; cotyledon, R; root, callus size index; $1=$ one end; $2=$ two ends; $3=$ two ends+ one side; 4= two ends+ two sides; $5=$ two ends+ two sides+ surface of explant. 
Table 2 Callus fresh weight induced on different explants of fenugreek using different concentrations $(0.5-6 \mathrm{mg} / \mathrm{L})$ of TDZ, NAA and 2, 4-D after 7 weeks of culture

\begin{tabular}{lllll}
\hline \multirow{2}{*}{ PGR (mg/L) } & \multicolumn{4}{l}{ Callus fresh weight $(\mathbf{g})$} \\
\cline { 2 - 4 } Control & \multicolumn{2}{l}{ Hypocotyl } & Root & Cotyledon \\
\hline TDZ & 0.5 & $4.25 \pm 0.0^{\mathrm{d}}$ & $0.0 \pm 0.0^{\mathrm{a}}$ & $0.0 \pm 0.0^{\mathrm{d}}$ \\
& 1 & $4.70 \pm 0.9^{\mathrm{a}}$ & $4.77 \pm 0.5^{\mathrm{a}}$ & $3.24 \pm 0.4^{\mathrm{ab}}$ \\
& 2 & $5.29 \pm 0.4^{\mathrm{a}}$ & $3.95 \pm 0.4^{\mathrm{ab}}$ & $4.98 \pm 0.8^{\mathrm{a}}$ \\
& 4 & $5.28 \pm 0.6^{\mathrm{a}}$ & $3.98 \pm 0.5^{\mathrm{ab}}$ & $2.63 \pm 0.4^{\mathrm{b}}$ \\
& 6 & $4.66 \pm 0.5^{\mathrm{a}}$ & $3.92 \pm 0.6^{\mathrm{ab}}$ & $2.53 \pm 0.4^{\mathrm{b}}$ \\
NAA & 0.5 & $0.31 \pm 0.1^{\mathrm{c}}$ & $0.42 \pm 0.1^{\mathrm{c}}$ & $0.30 \pm 0.1^{\mathrm{c}}$ \\
& 1 & $0.41 \pm 0.0^{\mathrm{c}}$ & $0.42 \pm 0.0^{\mathrm{c}}$ & $0.31 \pm 0.1^{\mathrm{c}}$ \\
& 2 & $0.51 \pm 0.0^{\mathrm{bc}}$ & $0.45 \pm 0.0^{\mathrm{c}}$ & $0.42 \pm 0.1^{\mathrm{c}}$ \\
& 4 & $0.57 \pm 0.1^{\mathrm{bc}}$ & $0.46 \pm 0.1^{\mathrm{bc}}$ & $0.43 \pm 0.1^{\mathrm{c}}$ \\
& 6 & $0.31 \pm 0.0^{\mathrm{c}}$ & $1.25 \pm 0.0^{\mathrm{bc}}$ & $0.35 \pm 0.6^{\mathrm{c}}$ \\
& 0.5 & $2.37 \pm 0.3^{\mathrm{b}}$ & $0.00 \pm 0.0^{\mathrm{d}}$ & $2.22 \pm 0.3^{\mathrm{b}}$ \\
& 1 & $2.00 \pm 0.3^{\mathrm{b}}$ & $0.00 \pm 0.0^{\mathrm{d}}$ & $2.04 \pm 0.3^{\mathrm{b}}$ \\
& 2 & $1.97 \pm 0.3^{\mathrm{bc}}$ & $0.00 \pm 0.0^{\mathrm{d}}$ & $1.33 \pm 0.2^{\mathrm{bc}}$ \\
& 2 & $1.76 \pm 0.3^{\mathrm{bc}}$ & $0.00 \pm 0.0^{\mathrm{d}}$ & $0.95 \pm 0.2^{\mathrm{bc}}$ \\
& 4 & $1.69 \pm 0.2^{\mathrm{bc}}$ & $0.00 \pm 0.0^{\mathrm{d}}$ & $0.94 \pm 0.2^{\mathrm{bc}}$ \\
& 6 & &
\end{tabular}

Values are means \pm standard error. Means value followed by different letter are significantly different at $0.05 \%$ probability level using Duncan multiple range test. PGR; plant growth regulator.
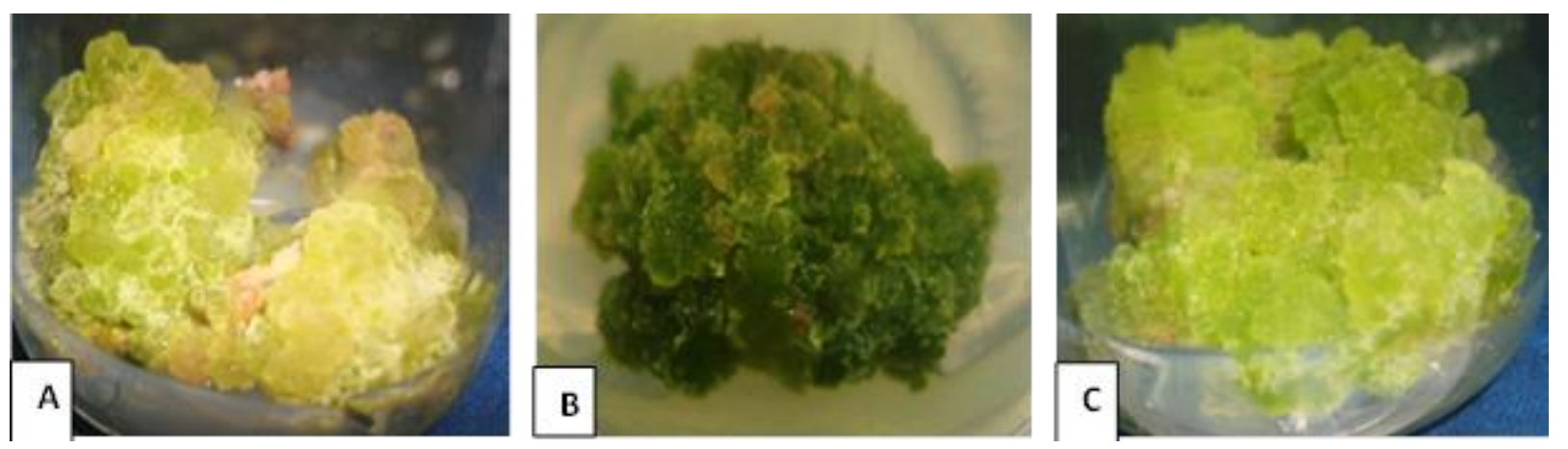

Figure 2 Callus induction in different explants of fenugreek using 2, 4-D, NAA and TDZ at 0-6 mg/L after 7 weeks of culture: A) yellowish green callus formation on hypocotyl explant with $4 \mathrm{mg} / \mathrm{L} \mathrm{2,4-D,B)}$ green callus formation on root explant with $0.5 \mathrm{mg} / \mathrm{L} \mathrm{NAA,} \mathrm{C)} \mathrm{light} \mathrm{green} \mathrm{callus} \mathrm{formation} \mathrm{on} \mathrm{root} \mathrm{explant} \mathrm{with} 0.5 \mathrm{mg} / \mathrm{L}$ TDZ.

\subsection{Total phenolic contents and antioxidant activity of fenugreek extracts}

The content of phenolic compounds was varied considerably, depending on the part of fenugreek extracted (Table 3). The highest phenolic content recorded was $246.9 \mathrm{mg}$ GAE/g DW on hypocotyl callus extract followed by $243.5 \mathrm{mg}$ GAE/g DW on root callus extract. This indicated that calli of hypocotyl and root showed phenolic content higher than seed extract which was $176.2 \mathrm{mg} \mathrm{GAE} / \mathrm{g}$ DW. Cotyledons callus gave the lowest value of phenolic content as $64.9 \mathrm{mg}$ GAE/g DW (Table 3). On the contrary, Ali and El Nour [25] reported that cotyledons callus showed higher phenolic content $(412.1 \mathrm{mg} / \mathrm{L})$ than hypocotyl callus $(211.2 \mathrm{mg} / \mathrm{L})$. Several studies have been performed on the quantification of polyphenols on fenugreek seed extracts by using Folin-Ciocalteau method with gallic acid as a standard. Most of these studies showed reported different values of total phenolic content. For example, Seasotiya et al. [4] reported high value of phenolic contents up to $186 \mathrm{mg} \mathrm{GAE} / \mathrm{g}$ DW in methanolic extracts of fenugreek seeds. While other 
studies reported a lower value as much as $9.7 \mathrm{GAE} / \mathrm{g}$ [3] up to $45.4 \mathrm{mg}$ GAE/g [26] and $78.1 \mathrm{mg}$ GAE/g [27]. Numerous factors can affect the secondary metabolic content in a plant species such as genetic, environmental origin, age of the seed, and processing of extracts. Rahmani et al. [28] found significant variations in the total phenolic content between four varieties of fenugreek from Algeria.

Table 3 Phenolic contents and free radical scavenging potential DPPH activity of fenugreek

\begin{tabular}{lll}
\hline Extract source & TPCs mg GAE/g & Activity \% $\mathbf{\text { SD }}$ \\
\hline Hypocotyl callus & 246.9 & $24.3 \pm 0.06$ \\
Root callus & 243.5 & $16.7 \pm 0.1$ \\
Cotyledon callus & 64.9 & $34.7 \pm 0.04$ \\
Seed & 176.2 & $44.3 \pm 0.04$ \\
\hline
\end{tabular}

Table (3) presented the results on in vitro investigation of the antioxidant activities of fenugreek extracts using DPPH radical scavenging techniques. Fenugreek seed extracts exhibited the highest antioxidant activity (44.3 $\pm 0.036 \%)$ followed by cotyledon callus extract $(34.7 \pm 0.04 \%)$, hypocotyl callus $(24.3 \pm 0.064 \%)$, and root callus extract $(16.7 \pm$ $0.1 \%)$. The results showed that the different extracts of fenugreek produced moderate to low radical scavenging activity. Variations in the antioxidant values of fenugreek seed extracts using DPPH radical scavenging activity has been reported by several authors. Haliem and Al-Huqail [29] studied the antioxidant potential of fenugreek seed among seven wild accessions found that the scavenging activity varies from $42.92 \%$ to $54.23 \%$. In contrast, higher values of antioxidant activity on fenugreek seed extract were also reported such as 67.9\% [4], 80.5\% [25] and 89.7\% [3]. On the other hand, the antioxidant activity of fenugreek calli extracts was reported on cotyledons and hypocotyl calli with scavenging activity of $91.5 \pm 0.16 \%$ and $85.46 \pm 0.29 \%$, respectively [25]. The genotype of fenugreek was the main source of variation on chemical constituents, therefore, antioxidant properties of seeds [1, 30].

\subsection{Antimicrobial activity of extracts}

The obtained extracts of fenugreek seeds and calli from roots, cotyledons and hypocotyl at a concentration of 100 $\mathrm{mg} / \mathrm{mL}$ were screened for their antimicrobial activities against four standard bacteria and one fungi using in vitro agar well diffusion method (Table 4). Hypocotyl callus exhibited the largest zone of inhibition recorded (19 mm) against E. coli. Methanolic extracts $(250 \mathrm{mg} / \mathrm{mL})$ of hypocotyls callus showed maximum inhibition zone of $11 \mathrm{~mm}$ against $S$. aureus [16]. On the other hand, in the present study, the smallest zone of inhibition recorded (10 mm) was against E. coli by root callus (Table 4). The maximum activity recorded by seeds extracts was $16 \mathrm{~mm}$ against $P$. aeruginosa. El Nour et al. [16] reported maximum inhibition zone of fenugreek seeds (petroleum ether extract at 250 $\mathrm{mg} / \mathrm{mL}$ ) was $17 \mathrm{~mm}$ against E. coli, while showed no activity against P. aeruginosa. In contrary, Sharma et al. [2] reported that methanol extract of fenugreek seed at $100 \mu \mathrm{L}$ showed no activity against E. coli and Staphylococcus spp.

Table 4 Antimicrobial activities of the fenugreek extracts

\begin{tabular}{|c|c|c|c|c|c|c|}
\hline \multirow{2}{*}{$\begin{array}{l}\text { Extract type } \\
(100 \mathrm{mg} / \mathrm{mL})\end{array}$} & \multicolumn{6}{|c|}{ Zones of inhibition diameter (mm) } \\
\hline & Ec & $\mathbf{P a}$ & Sa & Bs & Ca & Extract mean \\
\hline Seed & 13 & 16 & 12 & 15 & - & 14 \\
\hline Hypocotyl callus & 19 & 16 & 12 & - & - & 16 \\
\hline Cotyledon callus & 11 & - & - & 13 & 12 & 12 \\
\hline Root callus & 10 & 14 & - & 13 & 12 & 12 \\
\hline Microbial mean & 13 & 15 & 12 & 14 & 12 & \\
\hline
\end{tabular}

Bs: Bacillus subtitles, Sa: Staphylococcus aureus, Ec: Escherichia coli, Pa: Pseudomonas aeruginosa, Ca: Candida albicans. MIZD (mm): > 18 mm: sensitive; 14-18 mm: intermediate; < $14 \mathrm{~mm}$ : sesistance. 
In general, hypocotyl callus revealed the higher average activities (16 $\mathrm{mm})$ against studied bacteria followed by seed extract $(14 \mathrm{~mm})$. However, both extracts showed no activity against the studied fungus C. albicans which was similar to the result report by El Nour et al. [16]. However, root and cotyledons calli extracts exhibited activity against C. albicans with the same inhibition value $(12 \mathrm{~mm})$. Regarding susceptibility to different fenugreek extracts, P. aeruginosa appeared of intermediate sensitivity to most extract types with an average of 15 mm. Other understudy microbes showed, in general, complete resistance with average ranged 21-14 mm (Table 4). Several studies on antimicrobial activity of fenugreek seeds extract using similar microbial strains and different solvents have been reported with variable results.

\section{Conclusion}

A simple and reliable protocol for production of friable callus from in vitro seedling explants of Trigonella foenumegraecum was successfully achieved. Root segment was the better explants in callus induction. TDZ at $2 \mathrm{mg} / \mathrm{L}$ produced the maximum fresh weight of green callus. Cotyledons callus came second after seeds extract on antioxidant activity. Furthermore, hypocotyl callus extract showed higher phenolic content. The antimicrobial activity revealed by hypocotyl callus extract could be allied to the high phenolic content detected. These results anticipated that fenugreek callus unveiled high potential source for biologically active compounds. Further study on phytochemical analysis of fenugreek callus extract is essential to identify biocompounds liable for the biological activity.

\section{Compliance with ethical standards}

\section{Acknowledgments}

The authors would like to express their deepest gratitude to the Commission for Biotechnology and Genetic Engineering, National Center for Research, Khartoum, Sudan for providing research facilities.

\section{Disclosure of conflict of interest}

The authors declare that there is no conflict of interest regarding the publication of this article.

\section{References}

[1] Acharya S, Srichamroen A, Basu S, Ooraikul B and Basu T. (2006). Improvement in the nutraceutical properties of fenugreek (Trigonella foenum-graecumL.). Songklanakarin Journal of Science Technology, 28(1), 1-9.

[2] Sharma V, Singh P and Rani A. (2017). Antimicrobial activity of Trigonella foenum-graecumL. (Fenugreek). European Journal of Experimental Biology, 7 (1), 1-4.

[3] Al-Dabbagh B, Elhaty IA, Al Hrout A, Al Sakkaf R, El-Awady R, Ashraf SS and Amin A. (2018). Antioxidant and anticancer activities of Trigonella foenum-graecum, Cassia acutifolia and Rhazya stricta. BMC Complementary and Alternative Medicine, 18(1), 240.

[4] Seasotiya L, Siwach P, Bai S, Malik A and Bharti P. (2014). Free radical scavenging activity and phytochemical analysis of seeds of Trigonella foenum-graecum. Asian Pacific Journal of Health Science, 1(3), 219-226.

[5] Daffalla HM and Elsheikh AM. (2018). Secondary metabolites accumulation and production through in vitro cultures. In: Egbuna C, Ifemeje JC, Kumar S and Sharif N. (Eds), Phytochemistry: Marine sources, industrial applications, and recent advances, Apple Academic Press, USA.

[6] Aasim M, Khawar KM, Yalcin G and Bakhsh A. (2014). Current trends in fenugreek biotechnology and approaches towards its improvement. American Journal of Social Issues and Humanities, 128-136.

[7] Oncina R, BotõÂa JM, Del RõÂo JA and OrtunÄo A. (2000). Bioproduction of diosgenin in callus cultures of Trigonella foenum-graecumL. Food Chemistry, 70, 489-492.

[8] Jamshidi S, Lahouti M and Ganjeali A. (2014). Assessment of callus growth and bio-production of diosgenin in callus culture of Trigonella foenum-graecumL. Bulletin of Environment, Pharmacology and Life Sciences, 3, 191198.

[9] Gómez P, Ortuño A and Del Río JA. (2004). Ultrastructural changes and diosgenin content in cell suspensions of Trigonella foenum-graecumL. by ethylene treatment. Plant Growth Regulation, 44, 93-99. 
[10] Tsiri D, Chinou I, Halabalaki M, Haralampidis K and Spyropoulos CG. (2009). The origin of copper-induced medicarpin accumulation and its secretion from roots of young fenugreek seedlings are regulated by copper concentration. Plant Science, 176(3), 367-374.

[11] Safari G, Mahna N, Niazi A and Farsad N. (2018). Screening fenugreek genotypes for high callus induction and growth. International Journal of Agronomy and Agricultural Research, 12 (6), 146-154.

[12] Hassan SA and Jassim EH. (2018). Effect of $\mathrm{NaCl}$ and sorbitol on the production of some alkaloids of fenugreek cotyledons derived callus. Journal of Al-Nahrain University, 21 (1), 90-97.

[13] Rezaeian S. (2011). Assess of diosgenin production by Trigonella foenum graecum in vitro condition. American Journal of Plant Physiology, 6, 261-268.

[14] Burdak A. (2017). Effect of different plant growth regulators on callus induction of fenugreek (Trigonella foenum-graecum L.). MSc thesis, Department of Plant Breeding and Genetics, S.K.N. College of Agriculture, Jobner, India, 82.

[15] Prabakaran G and Ravimycin T. (2012). Studies on in vitro propagation and biochemical analysis of Trigonella foenum-graecum Linn. Asian Journal of Biological Sciences, 7 (1), 88 - 91.

[16] El Nour MEM, Ali AMA and Saeed BAE. (2015). Antimicrobial activities and phytochemical screening of callus and seeds extracts of fenugreek (Trigonella foenum-graecum). International Journal of Current Microbiology and Applied Sciences, 4(2), 147-157.

[17] Aasim M, Khawar KM, Sancak C and Özcan S. (2009). In vitro shoot regeneration of fenugreek (Trigonella foenum-graceum L.). American-Eurasian Journal of Sustainable Agriculture, 3(2), 135-138.

[18] Murashige T and Skoog F. (1962). A revised medium for rapid growth and bioassys with tobacco tissue culture. Physiologia Plantarum, 15, 473-497.

[19] Singleton V, Orthofer R and Lamuela-Raventos R. (1999). Analysis of total phenolic and other oxidation substrates and antioxidants by means of Folin-Ciocalteu reagent. Methods in Enzymology, 299, 152-78.

[20] Shyura LF, Tsunga JH, Chenb JH, Chiua CY and Lo CP. (2005). Antioxidant properties of extracts from medicinal plants popularly used in Taiwan. International Journal of Applied Sciences and Engineering, 3(3), 195-202.

[21] Kavanagh F. (1972). Analytical Microbiology. Academic Press, New York, London, 737-741.

[22] Lohvina HO, Makai S, Ditchenko TI, Reshetnikov VN, Spiridovich EV and Yurin VM. (2012). Induction of callus from leaves and stems of Trigonella foenum-graecum varieties. Acta Agronomica Óváriensis, 54 (2), 29-37.

[23] Abd Elaleem KG, Ahmed MM and Saeed BAE. (2014). Study of the in vitro callus induction Trigonella foenumgraecum L. from cotyledons and hypocotyls explants supplemented with various plant hormones. International Journal of Current Microbiology and Applied Sciences, 3(12), 486-493.

[24] Vaezi Z, Daneshvar MH, Heidari M and Chehrazi C. (2015). Indirect regeneration plant fenugreek (Trigonella foenum-graecum L.), with the use of plant growth regulators in vitro. Bulletin of Environment, Pharmacology and Life Sciences, 4(5), 103-108.

[25] Ali AMA and El Nour MEM. (2014). Antioxidant activity, total phenolic, flavonoid and tannin contents of callus and seeds extracts of fenugreek (Trigonella foenum-graecum L.). International Journal of Science and Research, 3 (10), 1268-1272.

[26] Pandey H and Awasthi, P. (2015). Effect of processing techniques on nutritional composition and antioxidant activity of fenugreek (Trigonella foenum-graecum) seed flour. Journal of Food Science and Technology, 52(2), 1054-1060.

[27] Belguith-Hadriche O, Bouaziz M, Jamoussi K, Simmonds MS, El Feki A and Makni-Ayedi F. (2013). Comparative study on hypocholesterolemic and antioxidant activities of various extracts of fenugreek seeds. Food Chemistry, 138, 1448-53.

[28] Rahmani M, Hamel L, Toumi-Benali F, Dif MM, Moumen F and Rahmani H. (2018). Determination of antioxidant activity, phenolic quantification of four varieties of fenugreek Trigonella foenum graecum L. seed extract cultured in west Algeria. Journal of Materials and Environmental Science, 9 (6), 1656-1661.

[29] Haliem EA and Al-Huqail AA. (2014). Correlation of genetic variation among wild Trigonella foenum-graecum L. accessions with their antioxidant potential status. Genetic and Molecular Research, 13 (4), 10464-10481. 
[30] Randhir R, Lin YT and Shetty K. (2004). Phenolics, their antioxidant and antimicrobial activity in dark germinated fenugreek sprouts in response to peptide and phytochemical elicitors. Asia Pacific Journal of Clinical Nutrition, 13 (3), 295-307.

\section{How to cite this article}

Osman MG, Daffalla HM, Ahmad M, Ali KS, Saleh SA and Hamza AA. (2020). Total phenolic content, antioxidant and antimicrobial activities of seeds and callus of Trigonella foenum-graecum Linn. GSC Biological and Pharmaceutical Sciences, 10(3), 01-09. 